\title{
Oração de paraninfo ${ }^{(*)}$
}

\section{Alcantara Machado}

E' sempre motivo de justa ufania, para quem a recebe, a investidura, que houvestes por bem conferir-me, srs. bachareis da turma de 1932. Neste momento, porém, o vosso gesto amigo tem uma significação toda particular, que reduplica o meu desvanecimento e a minha gratidão para comvosco. E' á direção atual da Faculdade que trazeis a solidariedade e o apoio, de que ela tanto precisa, para levar a termo a obra, apenas iniciada, da reintegração de nossa escola na plenitude de sua eficiencia prática e á alıura da missão, que lhe compete, na formação da conciencia juridica da nacionalidade. Ninguem podetá executar a tarefa, que urge, de renovar esta casa na materia e no espirito, sem a cooperação diuturna e esclarecida dos ilustres membros da Congregação, e ainda sem a colaboração prestimosa do funcionalismo, e tambem sem a adesão, a simpatia e a confiança da mocidade.

A escolha de meu nome, eu a recebo, não como um preito, que seria imerecido, e sim como o testemunho de que reconheceis a retidão intorcivel dos propositos que me animam e o desejo honesto, que me inflama, de servir á terra comum, servindo á causa sacratissima da educação nacional.

(*) Proferida na solenidade de formatura da última turma de bachareis pela Faculdade de Direito de São Paulo, a 19 de Março de 1932. 
Testemunhas sois de que se vem operando no organismo do velho instituto, em que estamos, uma transfusão de sangue generoso e saudavel, e, por isso mesmo, o seu ritmo vital é diferente do de outrora. O tronco secular continua com as raizes embebidas no humus opulento da tradição. Mas estão desaparecendo, aos bocados, os cipós da rotina que nele se enroscavam. Livres do abraço asfixiante das lianas, que lhes tolhiam o viço, e das ervas parasitarias que lhes roubavam a seiva, reverdecem os ramos, e nos rebentos que deles se desprendem abotoam as primeiras flores, que anunciam a abundancia da colheita proxima.

Tenho, na minha eleição, o vosso depoimento imparcial e expressivo de como venho realizando o programa que me tracei.

A refo:ma administrativa está quasi terminada com o saneamento da tesouraria, a instituição de uma contabilidade regular, a simplificação dos métodos burocraticos, o aparelhamento moderno das várias secções em que a secretaria se divide. Dentro em poucos dias virá a remodelação da biblioteca, ou, melhor, a transformação em biblioteca, por uma catalogação racional, das dezenas de milhares de volumes, que se aglomeram em nossas estantes, sem proveito para os estudiosos.

A reforma do edificio, começámo-la ha cêrca de um mês; e já em principios de Maio contamos inauguraruma aula, obediente aos mais rigorosos preceitos de higiene escolar, em que mestres e alunos tenham o ambiente agradavel e sadio, que convém á dignidade do ensino.

A reforma espiritual é a mais dificil. Mas é a mais necessaria. Lêstes porventura o que, ha poucos dias, na solenidade inaugural dos cursos da Universidade do Rio de Janeiro, disse Afranio Peixoto, com a lucidez implacavel de sua inteligencia de eleição e a sua destemerosa franqueza de grande homem de bem? Para alguns será uma caricatura maldosa, para outros uma fotografia não retocada dos institutos brasileiros de ensino superior. $O$ que ele vê em seu tôrno são mestres, aqs quais se nega o direito á vida, tão ridiculo é o estipêncío que lhes pagam, e se concedem, em troca, todos os direitos, inclusive o de julgar sem recurso, e o de não ensinar patavina; e alunos, aos quais se outorgam todas as regalias, menos a de exigir que 
lhes ensinem aquilo que devem aprender. Os primeiros, sem estímulo e sem entusiasmo, desempenhando-se displicentemente, como qualquer amanuense, das funções que lhes incumbem. Os ultimos, com a preocupação exclusiva de "passar», seja lá como fôr, por decreto, por média, com a ajuda imoral dos empenhos, com o auxilio indecoroso das colas, concentradas assim todas as suas ambições, não na posse do conhecimento, mas na posse do diploma. A lição, reduzida a um monólogo, cujo termo é esperado ansiosamente pelo orador e pelo auditorio, com os ouvidos atentos ao bater da hora. O aproveitamento dos discipulos, apurado ás cegas, na loteria dos exames. E por aí continua o libelo tremendo: o eminente medico-legista vai abrindo, viscera por viscera, e dissecando, tecido por tecido, o ensino superior do país, como faria a um cadaver, largado sôbre a mesa do necroterio.

Somos suspeitos, todos nós, para julgar da procedencia de acusações que a todos nós atingem.

O que podemos afirmar serenamente é que o remédio dos males apontados está pura e simplesmente no cumprimento da lei. Ha professores indignos ? Cumpra-se a lei: corre á administração o dever de puni-los; e podem puní-los os proprios alunos, mediante a opção pelos cursos dos livies docentes. Existem alguns, que se enquistam em suas cadeiras, e, agarrados a elas, permanecem durante trinta, quarenta, cincoenta anos, atravancando a disciplina, prejudicando gerações sôbre gerações de estudantes, impedindo a renovação do professorado? Cumpra-se a lei: sejam eles aposentados compulsoriamente. $\mathrm{O}$ ensino obedece a processos condenados pela pedagogia? Cumprase a lei: constituam-se seminarios, centros de debates e de pesquizas, clínicas judiciarias, que representam para as ciencias sociais o que representam os laboratorios para as ciencias da da natureza. O exame é um processo reprovado e falido ? Cumpra-se a lei: submetam-se os discentes a exercicios piaticos e provas parciais, rigorosamente fiscalizadas, com influência proeminente no julgamento final.

Mas do respeito á lei quem deve dar o exemplo ? O govêrno. E hoje, como sempre, o govêrno é o primeiro a violentá-la, conspurcá-la, prostitui-la a todos os sofismas, enervando-lhe a apli- 
cação, desnorteando, desautorando, desmoralizando os seus executores, rompendo, á menor pressão dos interesses contrariados, os rasgões por onde se precipita a torrente dos abusos.

O desalinho e a displicencila das congregações, o ceticismo com que a maioria dos escudantes encara as tentativas de reerguimento do ensino, vem daí: vem da traqueza e da covardia dos poderes publicos, deante das pretensões mais absurdas e atrevidas.

Não desanimemos. Dia virá, em que a evidência dos maleficios decorrentes da incapacidade governamental em materia de tamanha delicadeza levará o Estado a devolver ás Congregações a autonomia, de que precisam, para o saneamento definitivo do ensino superior.

Têmo-la restrita a certos assuntos. Podemos e devemos aproveitá-la para a inclusão de novas disciplinas indispensaveis á formação profissional e cultural do jurista. Assim, a legislação social. Assim, o direito internacional privado. Assim, a história do direito, e particularmente do direito brasileiro.

Todas são igualmente necessarias. A última tem como nenhuma outra o sainete da oportunidade.

Se por uma desgraça fosse obrigado a desfazer-me dos meus livros, dessas páginas que são para mim o pão e o vinho quotidianos, e a despedir-me dêsses escritores dos quais me sinto concidadão pelo espirito, os uitimos de que me apartaria, com o coração esquartejado, seriam sucessivamente os de história universal, e do Brasil, e de São Paulo.

Amar é compreender; e assim não pode amar de verdade a sua terra quem não the saiba o passado. Como ha de prezar uma obra aquele que desconhece quanto custou em suores e vigilias, em sofrimentos e sacrificios, aos operarios que a conceberam e edificaram?

Houve quem acusasse a história de ser uma professora de desânimo. Que injustiça! O que ela nos ensina é precisamente o contrário: a confiança, a energia, a coragem.

Para consolar-nos dos males e das miserias presentes, nada mais salutar do que um relance de olhos sôbre os tempos que se foram. Encontramos por vezes como que um éco de nossas preocupações de momento. Que tem a guerra do Peloponeso, 
velha de tantos seculos, com a atualidade paulista? Nada. Evidentemente. Bate-nos, entretantos, mais apressado o coração, quando lemos em Tucídides a explicação da luta encarniçada $\mathrm{em}$ que Atenas sucumbiu: "Espar ta tinha inveja de nós».

Mazelas, que nos parecem específicas de nossa idade, de nossa terra, vamos encontrá-las em países distantes no espaço e no tempo. Se compulsardes, por exemplo, os livros suculentos em que Gaston Boissier reconsticúi com vivacidade insuperavel a Roma dos Césares, vereis com surpreza que nenhuma diferença existe, em substancia, entre os costumes politicos de então e os de hoje, ou, melhor, de ôntem. Longe de ser uma invenção dos politiqueiros indigenas, a corrupção eleitoral constituia, já naquelas terras afastadas, uma verdadeira ciencia. Quintus Cicero, irmão do Orador, chegou a publicar um tratado exaustivo sôbre a materia: "De petitione consulatus". A cabala, no campo de Marte, onde o candidato se postava para uma larga distribuição de promessas, de apertos de mão e de sorrisos, a compra descarada de votos pelos "sequestres", que eram os galopins eleitorais da epoca, as inscrições nas paredes com apelos $\mathrm{im}$ favor do postulante, a concentração dos votantes nas tavernas, antes e depois do pleito, para se encherem de secos e molhados, tudo isso vem de muito longe. A propria intervenção das mulheres na vida pública é uma criação romana. Provam-no as inscrições murais de Pompea, correspondentes aos cartazes gritantes da atualidade, em que sózinha, ou com o marido, ou com os filhos, a matrona solicita para o seu predileto o sufragio do povo: "Fortunata cupit. Sema cum pueris cupit. Hilario cum sua rogat. "Era tamanha por vezes a disputa entre as facções que, na impossibilidade de um entendimento, elas entregavam ao imperador a escolha dos magistrados. Talqualmente se fazia ainda ha pouco, em certo país muito nosso conhecido, onde as influências locais deteriam ao presidente da República a indicação dos governadores.

Poderia multiplicar indefinidamente as aproximações entre o passado e o presente, na esfera política, no dominio filosófico, no campo das letras, no terreno da ética e dos costumes.

$\mathrm{Na}$ esfera política: os govêrnos tradicionais, convertidos pelo abuso do poder em fabricantes inconcientes de revoluções; 
as revoluções, esquecidas, quando vitoriosas, dos principios que lhes asseguraram o triunfo. No dominio filosótico: o espirito humano lembra um pêndulo condenado a oscilar eternamente entre o materialismo mais grosseiro e o mais puro espiritualismo, porque as doutrinas novas não passam de simples: máscaras dessas duas concepções fundamentais do universo. No campo das letras: faz poucos dias, que, na mais jovem de nossas escolas superiores, alguem tomava como assunto de sua preleção inaugural o parnasianismo na literatura latina. No terréno da ética e da moral: se um dia vos sentirdes escandalizados pelo contraste entre o luxo e o conforto de que vivem cercados certos lulús da Pomerania ou gatos felpudos e a miseria em que se estiolam tantas crianças á mingua de pão e de carinho, Plutarco vos dirá que, já no tempo de Cesar, o mesmo espetáculo arrancava o mesmo grito de indignação ás almas bem formadas. "Dar-se-á que, em vossa terra, as mulheres não tenham tilhos?», perguntava ele, deante dos mimos dispensados aos macacos e cachorros de estimação. E quantas de nossas con. temporaneas merecem que em seu tumulo se grave, não o epitafio magnifico da mãe de familia, "domum servavit, lanam fecit», mas aqueloutro, luminoso na aparencia e tremendo na realidade, "saltavit et placuit?»;

Mas se a história se repete (dir-me-ão talvez), têm razão os que a acusam de constituir uma escola de desalento. Não. O que ela encerra, acima de tudo, é uma lição de tolerancia e de sabedoria. Não ha, nem houve nunca, uma idade de ouro na vida da humanidade. Não ha, nem houve em tempo algum, instituições perfeitas e doutrinas políticas ou sociais impereciveis. Não ha, nem houve jamais, quem conseguisse reformar a natureza humana a goipes de decreto. Não ha, nem pode haver, melhoria social, reforma fecunda, progresso efetivo, que não seja resultado de uma transação entre o passado e o futuro: "Praeterito semine, futura serenda». Evolução, e não revolução, eis a fórmula que a história nos impõe. O exame sereno das grandes convulsões políticas confirma o juizo insuspeito de Anatole France: os vencedores só nos trazem de novo a sua inexperiencia.

No estudo do passado aprendemos tambem a não deses- 
perar do presente e a confiar nos dias que hão de vir. A não desesperar do presente: por mais sombrio que nos pareça o ambiente, sabemos que não é eterno o poder das trevas. A confiar nos dias que hão de vir: apesar dos êrros e das fraquezas e dos recuos irreparaveis da argila humana, o mundo de hoje é grandemente superior ao mundo de ôntem. Vive-se cada vez mais. E cada vez melhor. Sobram os testemunhos de que o espirito se tem emancipado lentamente, mas incessantemente, da besta; e que vai crescendo todos os dias, em altura, em largura, em profundeza, a solidariedade entre os homens; e que, pela multiplicação dos institutos de previdencia e de amparo aos fracos e aos pequeninos, estamos reconquistando aos poucos o terreno usurpado pela injustiça, pela miseria, pelo sofrimento; e que a humanidade contemporanea é mais livre, mais sadia, mais instruida, mais próxima, do que a antiga, da justiça e da caridade.

Nenhum povo existe, que possa tirar de sua história ensinamentos mais belos e estimulos mais saudaveis que o brasileiro, e, sobretudo, o paulista. Cada página de nossa história é um pergaminho de nobreza. Daí o nosso orgulho. Orgulho fundado, porque vem do conhecimento de quanto deve a patria comum aos nossos maiores, e porque nos diz a conciencia, que estamos continuando com dignidade e firmeza a obra dos Dias Paes, dos Andradas e dos Feijós.

De orgulhosos houve sempre, desde os tempos da colonia, quem nos averbasse. Falando de jactanciosos, o poeta Garção nos metia a bulha numa versalhada com pretensões a sátira:

\section{Parece-me que estou entre paulistas Que eructando congonhas me aturdiam Com a fabulosa ilustre descendencia De seus claros avós}

Ainda nesse ponto seria legítima a nossa prosapia. Está desfeita para sempre a lenda que os povoadores de São Vicente vinham da ralé das vilas e dos presidios da Metropole. Entre os fundadores das principais familias vicentistas se encontram fidalgos da mais pura linhagem. Mas, afinal, tudo isso pouco 
importa. O de que nos orgulhamos não é do sangue que nos transmitiram, mas do monumento que edificaram.

Se quereis conhecer esses claros avós e prezá-los de verdade, consultai de preferencia os trabalhos de Pedro Taques, de Capistrano, de Taunay, de Oliveira Viana, e compulsai os documentos do tempo que só agora estão sendo exumados dos hipogeus dos arquivos: as atas das municipalidades, os inventarios e testamentos, as narrativas dos primeiros viajantes, as. cartas dos primeiros missionarios. Entrareis assim na intimidade dos nossos maiores, e podereis com algum esfôrço de imaginação acompanhá-los na vida aspera dos primeiros tempos, em luta incessante contra o selvagem e o pirata e a natureza formidavel, privados do conforto mais elementar, morando em casas de taipa de mão, cobertas de palha, vestindo o burel grosseiro, e, com tudo isso, lavrando a terra, expulsando a floresta, semeando cidades. Mais tarde, quando a conquista se consolida, é a arrancada para o sertão em busca dos braços que os latifundios reclamam e depois á procura do ouro e das esmeraldas. Ei-los que vão, para o desconhecido, arrastados pelas águas voraginosas do Tieté; e devassam a mata impérvia; e galgam as serranias agrestes, e palmilham a vastidão intérmina dos campos. Aqui, a maleita; acolá, o bugre insidioso; adeante, a fera bravia; mais além, o deserto, a fome, a sêde. Que importa? Avançam sempre. Alcançam de um lado o rio da Prata; de outro, o Paraguai; chegam ao coração da Baía, do Ceará, do Piauí, atingem as margens do Amazonas. Voltam os mais felizes. Mas de tal forma envelhecidos e desfigurados, que, por vezes, os parentes se recusam a reconhecê-los. Mas dentre os que partem quantos ficam no caminho! Nenhưm deles se esquece, quando a morte se aproxima, de fazer o seu testamento, "afim de pôr a alma no caminho da salvação". Este se declara "doente de uma frechada no sertão dos Abueus»; estoutro, "doente de uma mordida de cobra»; aquele "doente de uma doença que Nosso Senhor lhe deu neste sertão dos Carijós» Em cada uma dessas frases bem se percebe um mundo de sofrimentos e de heroismos.

Tanto bastaria para que nos envaidecessemos de nossa linhagem. Mas, alêm de uma heroicidade sem par, os nossos 
antepassados eram de uma altivez sem limites, de uma honestidade sem jaça; e é o que mais deve engrandecê-los aos olhos da posteridade.

Se a todos aproveita, o conhecimento da vida da humanidade e particularmente da patria constitúi um dever essencial para nós outros, homens da lei.

Em sua oração, tão suculenta na substancia quanto formosa na forma, o vosso intérprete, meus jovens colegas, abordou, com felicidade, um dos pontos que eu tinha escolhido como tema desta minha pobre alocuçã̃o.

Corre ventapôpa, desde muito, a afirmação de que a Constituição de 1891 não tem raizes no que se costuma chamar vagamente a realidade brasileira. Dois escritores contribuiram, sobretudo, para a difusão dêsse preconceito em nosso meio; Alberto Torres e Oliveira Viana. Ambos ilustres. Nenhum deles infalivel. Alberto Torres (quem o diz é Levi Carneiro) sofreu como ninguem as decepções da politicagem no seu Estado, e, por isso mesmo, em toda a sua obra se percebe o travo dessas amarguras. A Oliveira Viana (peço venia para dizê-lo) falta, apesar de seu merecimento invulgar, a qualidade essencial, que é, para servir-me de uma expressão de Paulo Bourget, a submissão ao objeto. Não se utiliza dos fatos que observa para edificar a sua doutrina. Serve-se deles para justificar os seus pontos de vista preconcebidos e assentes.

Para assegurar, como costumam fazer dogmaticamente os nossos Bryce de pechisbeque e os nossos Cooley de cacaracá, sugestionados pelos exemplos daqueles dois eminientes pensadores, que o pacto de 24 de Fevereiro representa apenas uma obra de ideologos, sem atenção ás condições do meio, é preciso desconhecer um ou ambos os termos da equação: ou a Constituição, ou o Brasil, ou êste e aquela.

Quais são, com efeito, os principios cardeais da Constituição de 1891 ?

Primeiro, a fórma republicana. Mas, quando se proclamou a República, essa fórma de govêrno era uma aspiração que datava de mais de um seculo. Morreu por ela Tiradentes em 1789. Os revulucionarios de Pernambuco em 1817. A idéa reaparece 
na Constituinte de 1823. Triunfa um momento com a Confederação do Equador em 1824. Ressurge no Parlamento depois do 7 de Abril. Em 1835 levantam-na de novo os farroupilhas de Piratinim. Em 1837 chega á Baía a vez de manifestá-la. Ergue-a como bandeira de Partido em 1870 a facção avançada do liberalismo. Começa então uma propaganda tenaz, que se estende por vinte anos. Pode-se dizer, sem pecar contra o Espirito Santo, que fosse um exotismo no Brasil de 1891, uma idéa que vinha assim repontando, com breves intermitencias, durante um seculo?

Segundo, o regimen federativo. Nada mais conforme ás condições geograficas e ás tradições do país. $\mathrm{O}$ nosso particularismo (escreve Manuel Bomfim) teve a mesma origem daquele de toda a America. Foi o produto de uma ressurreição feudal, determinada pelas necessidades da colonização. As donatarias tiveram cartas outorgadas, como o primeiro estabelecimento inglês nas costas da Virginia. Muito de indústria, para que se não formasse a conciencia nacional, a Metrópole conservou sempre desunida, em compartimentos estanques, as várias capitanias. De sorte que, até o comêço do seculo passado, não havia brasileiros. Havia, sim, paulistas, gaúchos, baianos, pernambucanos, paraenses. Por isso mesmo, proclamada a Independencia, a Federação, que fôra o sonho dos Inconfidentes, lança raizes na opinião pública e só não logra verter-se em realidade pela resistencia que lhe opuzeram os Andradas, receiosos de que ela trouxesse comsigo o desmembramento. Logo, porêm, a revolução pernambucana de 1824 arvora a bandeira federativa. Por volta de 1830 surgem na capital do Imperio varios órgãos de imprensa, como a "Republica», o "Tribuno", a «Luz Brasileira», em que se préga abertamente a República Federal. Depois do 7 de Abril, é no parlamento que a idéa repercute. A Camara dos Deputados são apresentados em 1831 varios projetos, em que sucessivamente se propõe que o govêrno do Brasil seja federal; que, vitalicio na pessôa de Pedro II, se torne, depois, temporario, na pessôa de um presidente das provincias confederadas; que cada provincia nomeie uma assembléa para fazer a sua constituição particular. Não preciso lembrar o pensamento em que se plasma o A to Adicio- 
nal, onde se concedem franquias consideraveis ás provincias de então; nem preciso recordar que, deturpado esse Ato pela lei interpretativa de 1840 , conquista dos elementos reacionarios, São Paulo e Minas se levantam de armas na mão em defesa de suas prerrogativas. A descentralização, no verdadeiro sentido do "self-government», é um dos pontos por que se batem os liberais históricos e progressistas no manifesto de 1879. A Federação figura no do Partido Republicano, lançado a 3 de Dezembro do ano seguinie. Passados quinze anos, Joaquim $\mathrm{Na}$ buco apresenta um projeto destinado a satisfazer as velhas aspirações do povo brasileiro. Em 1889, é todo o Partido Liberal que se decide pela monarquia federativa; e Ouro Preto, representante maximo da ala moderada, inclúi entre as promessas de seu govêrno, que seria o último do regímen, a autonomia dos municípios e a descentralização das provincias, ao mesmo tempo, em São Paulo, Antonio Prado se converte ao novo credo. E ha quem diga que uma idéa assim vigorosa e 1adificada na conciencia nacional, constante do programa de todos os partidos, foi sancionada levianamente, pelos constituintes de 91 !

Terceiro, o presidencialismo. A escolha estava limitada, ao tempo em que se votou a Constituição, entre o sistema par lamentar e o sistema presidencial. Qual deles o mais consentaneo com as tradições e as necessidades do país? Consentaneo com as nossas tradições não era o parlamentarismo. Tivémo-lo sómente «in nomine», durante o segundo Imperio. Confessam-no todos quantos têm estudado a evolução política da nacionalidade. "O imperador impera, governa e administra", proclama-o da tribuna do Senado, em 1869, o visconde de Itaboraí, presidente do Conselho. Basta dizer que em 1853 a pasta da Guerra é confiada a Belegarde, sem assento em nenhuma das Camaras, para mostrar o que foi entre nós a comedia parlamentarista. O sistema parlamentar não era consentaneo, de outra parte, com as nossas necessidades. São os proprios Oliveira Viana e Alberto Torres que o confessam, quando reclamam o tortalecimento do poder central.

Estais vendo, meus queridos amigos, por essa amostra, quanto é oportuno, em momentos de confusão como êste, a consulta ao passado. Tem toda a razão Emilio Faguet, quando 
escreve que o radicalismo ou extremismo é a molestia dos políticos que não sabem história.

Ainda bem que, pelo órgão do vosso orador, demonstrais compreensão exata da gravidade do momento e dos remedios que reclama.

As suas palavras, que traduzem o sentimento de toda a turma, enchem-nos de orgulho e de esperança.

Perguntaram certa vez a La Fayette o que tinha feito ele pelo triunfo de suas convicções liberais durante o govêrno despotico do primeiro Napoleão. Aquele, a quem Montalembert chamou o mais cavalheiresco dos revolucionarios, aquele que nos dois mundos verteu sangue pela liberdade, respondeu simplesmente: "Conservei-me de pé».

Quando um dia vos perguntarem o que fez esta Faculdade durante a noite que pesa sôbre a nossa terra, podeis responder que ela, toda ela, mestres e alunos, se mantiveram coesos, de pé, de cabeça erguida, com os olhos voltados para Deus, confiantes na redenção, pelo direito, de São Paulo e do Brasil. 